\title{
Leveraging the census for customer analysis
}

Received (in revised form): 26th May, 2003

\section{Barry Leventhal}

is Head of Analysis and Modelling in the UK for Teradata, a division of NCR. He also chairs the Census \& Geodemographics Group of the Market Research Society. Prior to Teradata, Barry was Statistics Director of a CRM consultancy for nine years and held a similar post in a census agency for five years. He worked in market research for ten years, at the start of his career.

Abstract Outputs from the 2001 census are providing market analysts with updated information on the size and structure of the UK population at the start of the 21st century. The objective of this paper is to show how the new data will be a unique and valuable resource for customer analysis. After setting the scene in the first section, the second section of the paper highlights the main developments affecting census outputs and their dissemination. The third section describes ways in which the data can add value for customer analysis.

\section{INTRODUCTION}

The year 2003 sees the release of the main results from the latest UK population census, which took place in April 2001. The census is arguably the information bedrock that underpins all market analysis undertaken in the UK. The purpose of this paper is to show that the census also has valuable applications to customer analysis, for 'business to consumer' sales and marketing. Furthermore, it will be shown that unprecedented opportunities exist to harness together detailed census and customer databases for analytical developments that were not previously viable.

The 2001 census contained a number of major innovations in data collection methods and the dissemination of results.

Barry Leventhal

Teradata Vision, NCR Limited, 206 Marylebone Road, London NW1 6LY, UK.

Tel: +44 (0)20 8905 2634; e-mail: barry.leventhal@ncr.com
A full review of census developments goes beyond the scope of this paper: the interested reader is directed to other research papers, census guides or online sources. ${ }^{1-4}$ This paper first highlights the key developments affecting census outputs and their dissemination, which have a direct impact on the opportunities to leverage the census for customer analysis; these developments are summarised in the section below.

The third section describes ways in which the 2001 census data can add value for customer analysis. Census data may be leveraged in two main ways: as sources of demographic information and as sources for geographical targeting. The main focus, however, will be on the new opportunities to use detailed census and customer databases in combination, for custom-built analytics.

\section{KEY DEVELOPMENTS IN CENSUS OUTPUTS AND DISSEMINATION OF RESULTS}

\section{One number census}

A major development for the 2001 census has been the introduction of the 'one number census' (ONC) as a strategy to overcome the issue of under-coverage 
of the population. Although the 1991 census in England and Wales achieved a response rate of 96 per cent exceptionally high by market research standards - the published outputs nevertheless omitted 1.2 million people, which affected the usefulness of census results. In 2001, the response rate fell further, to 94 per cent in England and Wales, with significantly lower rates in inner London and across some demographic groups.

The ONC goal was to correct for under-coverage as part of the census processing, so that the published results achieve a 100 per cent response rate and thus represent the entire population resident in every area of the UK. This was achieved with the help of a large post-census coverage survey and some highly sophisticated estimation and imputation techniques: more details of the process may be obtained from the Office for National Statistics (ONS) website. $^{4}$

The outcome is that census results for all parts of the UK can be used in the knowledge that there are no coverage gaps or missing people to worry about, and this applies to all outputs at all levels of geography.

\section{Output geography}

The choice of geography for publishing census results is critical because, for confidentiality reasons, individual-level data that could identify people or households cannot be disclosed.

Outputs can be produced for a wide range of geographies, however, so that results may be compared across all areas, for a given level of geography. This capability has been enhanced for the 2001 census, through the creation of a new geography for small areas.

This geography, known as output areas (OAs), has been created from the database of census results, using an automated system developed using geographical information system technology. ${ }^{5}$ By constructing the OAs from actual census results, they could be designed to achieve a target population size, have regular shapes and follow 'natural' boundaries (where feasible), and be as homogeneous as possible, while nesting within the necessary administrative geography (primarily wards and local authority districts).

The OAs have been built as combinations of complete unit postcodes, subject to the caveat that postcodes spanning ward boundaries had to be split, in order to fit the OAs within administrative geography.

For England and Wales, the target size per OA was 125 households, resulting in the creation of 175,000 OAs in total. For comparison, the enumeration district (ED) geography used for the 1991 census contained, on average, 181 households per ED and there were 110,000 EDs in England and Wales. Thus the new OA geography is highly granular; additionally, each OA has been constructed to be as homogeneous as possible, in terms of home ownership and dwelling type. The implication therefore is that 2001 census data for OAs will be more segmented and therefore a more powerful discriminator than their 1991 counterpart.

Similar methods were employed in Northern Ireland for constructing OAs, while a different approach was adopted in Scotland: the Scottish OAs again comprise groups of unit postcodes, however each area typically contains around 50 households.

The OAs are defined geographically by means of digital boundary files and grid references of their centres. A 'Postcode to Output Area' directory will enable postcoded records to be assigned to OAs so that their census data can be extracted. 


\section{Data processing}

The bulk of the data entry and coding operations for the 2001 census were automated, with the aid of electronic scanning technology and handwriting recognition software. Automation enabled 100 per cent of the data to be captured; in previous censuses, questions requiring substantive manual coding, such as occupation, could only be coded for a 10 per cent sample of forms.

The benefit of 100 per cent data capture is particularly important to results for small areas, such as the OAs described above. The 1991 small area data for ' 10 per cent variables' contained very low counts and was therefore highly unstable. Therefore having '100 per cent variables' will lead to greatly improved accuracy when, for example, customer data are linked to census data at OA level.

\section{Social grade approximation}

A major shortcoming of the census for commercial users has always been the inability to analyse by social grade: the 'ABC1' system used for advertising and marketing. For the 2001 census, the Market Research Society's Census \& Geodemographics Group developed an algorithm for deriving an approximate social grade from other information such as occupation, employment status and housing tenure. ${ }^{6}$ The Census Offices agreed to apply this algorithm on the census database and provide output tables on approximate social grade. This will allow social grade profiling to be included alongside other demographic profiles, or areas to be targeted on penetration of 'ABs' and so on.

\section{Census access}

Access to census data has been improved in two ways. First, users wanting selections of data, such as key statistics for all local authority districts or high-level counts for a single area, can access it over the web via the Neighbourhood Statistics Service. Neighbourhood Statistics is an internet-based service with the aim of meeting the information needs of the National Strategy for Neighbourhood Renewal, and covers more than just census data.

Users requiring large national data sets can obtain 'bulk supply' on electronic media such as CD-ROM. The analytic applications described in this paper will fall into this category.

The second improvement, which represents a breakthrough for users, is that all standard outputs from the 2001 census are being made available effectively free of charge. This applies to all reports and standard outputs accessible via the web. For standard results obtained via other media, such as on CD-ROM, only the costs of supplying the information may be recovered through charges.

This new charging strategy, which is known as 'Census Access', was initiated by the ONS for England and Wales. Equivalent arrangements have been set up by the Census Offices for Scotland and Northern Ireland, thus making UK census data available free of charge to all users.

\section{Which census output to use}

The Census Offices have designed a wide range of packages of statistics from the 2001 census - see, for example, the ONS Output Prospectus ${ }^{4}$ for further information. For customer analysis, the main output of interest will be the census area statistics (CAS), a collection of around 7,000 counts for each output area, organised as a collection of cross-tabulations of the question topics 
Table 1a: Questions asked of a household in the 2001 census

\begin{tabular}{l}
\hline Household questions \\
\hline Type of accommodation \\
Whether accommodation is self-contained \\
Number of rooms \\
Whether have sole use of bath/shower and toilet \\
Lowest level of accommodation \\
Central heating \\
Car/van ownership \\
Ownership of accommodation and type of landlord \\
Household members, the relationships between \\
them \\
\hline Individual questions \\
\hline Sex \\
Date of birth \\
Marital status \\
Address one year ago \\
Country of birth \\
Ethnic group \\
Religion (voluntary) \\
Knowledge of Welsh language (in Wales only) \\
Limiting long-term illness \\
General health \\
Provision of care \\
Academic and vocational qualifications \\
Professional qualifications \\
Economic activity \\
Time since last employment \\
Employment status (employed or self-employed) \\
Size of workforce and place of work \\
Occupation \\
Supervisor status \\
Industry \\
Hours usually worked \\
Name and address of employer \\
Method of travel to work \\
\hline
\end{tabular}

and derived variables (see Tables $1 \mathrm{a}$ and 1b). The CAS data are also eagerly awaited by the geodemographics industry to fuel a new generation of area classification products.

\section{APPLICATIONS TO CUSTOMER ANALYSIS}

Applications of census data to customer analysis fall into two categories of use, which may be deployed either separately or in combination:

- demographic: essentially using the census as a source of demographic information
Table 1b: Examples of derived variables

\begin{tabular}{l} 
Household variables \\
\hline Household size (persons) \\
Number of adults in household \\
Number of adults in employment in household \\
Household dependent children \\
Pensioner household \\
Household composition \\
Household type \\
Living arrangements (marital status/relationship) \\
Rooms required (occupancy measure) \\
Multiple ethnic identifier \\
\hline Family variables \\
\hline Family dependent children \\
Family status (circumstances) \\
Family type \\
\hline Person variables \\
\hline Economic activity \\
Distance travelled to work \\
NS socio economic classification \\
Approximated social grade
\end{tabular}

- locational: using the census as a tool for targeting geographical locations.

The relevance of the census for 'business to consumer' marketing will depend on the extent to which the customer base is segmented, either demographically or geographically (or both). In the author's experience, there are very few products that are so widely used as to be totally 'unsegmented': one example might be a brand such as Coca-Cola, which is universally consumed. Even in this case, however, consumption rates are likely to vary significantly between age groups.

\section{Demographic applications}

Marketers can gain a better understanding of their customers by profiling using any combination of the demographics in the census statistics database. The richness of these data can be seen from the set of questions asked 
in 2001, which are summarised in Table 1a. To this list can be added a host of classifications derived from census responses, such as approximate social grade mentioned above - examples of the derived classifications are shown in Table $1 \mathrm{~b}$.

\section{Demographic profiles}

Demographic profiles are typically a two-step operation.

\section{a) Area profiling}

The first stage is to determine the geographical area where the majority of customers reside and obtain the census profile of its population. In other words, this gives a picture of the base population from which the company's customers have been drawn. For products available nationally, this base will therefore be the UK (or possibly just the Great British) population. For a business with a limited trading area, such as a restaurant, the base might be the population living within $\mathrm{X}$ miles, or $\mathrm{Y}$ minutes drive time, of the restaurant location. An example taken from an area profile report for the county of Dyfed, based on the 1991 census, is shown in Table 2.

\section{b) Customer profiling}

The second stage is to obtain the corresponding census profile for the population of customers who reside in that trading area, or for a representative sample of customers. The customer profile is interpreted by comparison with the base population profile from stage (a) and equivalent profiles may also be usefully produced for subsets of customers, such as 'high value' vs 'low value', various customer segments or purchasers of different products.

The confidentiality requirements mentioned previously prevent customers from being matched to the census database at an individual level and profiled on their actual characteristics. Therefore, step (b) works by assigning each customer to their OA, based upon their home postcode, and attaching the OA profile as a set of counts or proportions for the various demographic categories. A summary customer profile can then be created, effectively representing the characteristics of the locations where customers reside. An example from part of a 1991 census customer profile is shown in Table 3. Experience has shown that if the customers were significantly over or under-represented in certain demographic groups, this would be evident from their census profile.

The design of the OAs combined with 100 per cent coding of all variables will facilitate customer profiling in this way. Postcoded customer records may be assigned to OAs via a simple look-up table and their profiles should be 'sharper' and more discriminatory.

\section{Locational analysis}

Each OA has a known geographical location and therefore the census may be used to find and map the areas that contain certain types of people. For example, if a retailer undertakes the demographic analysis described in the last section and finds that its customers tend to be, say, 'middle-aged, Social Grade AB, without children', then it could apply these criteria to search for potential site locations in areas with the highest concentrations of these characteristics.

In an equivalent way, areas may be ranked on the penetration of target customer characteristics in order to provide a 'hit list' of the best towns for locating a store, the best postal sectors for marketing activity and so on. 
Table 2: Example from area profile report using 1991 Census

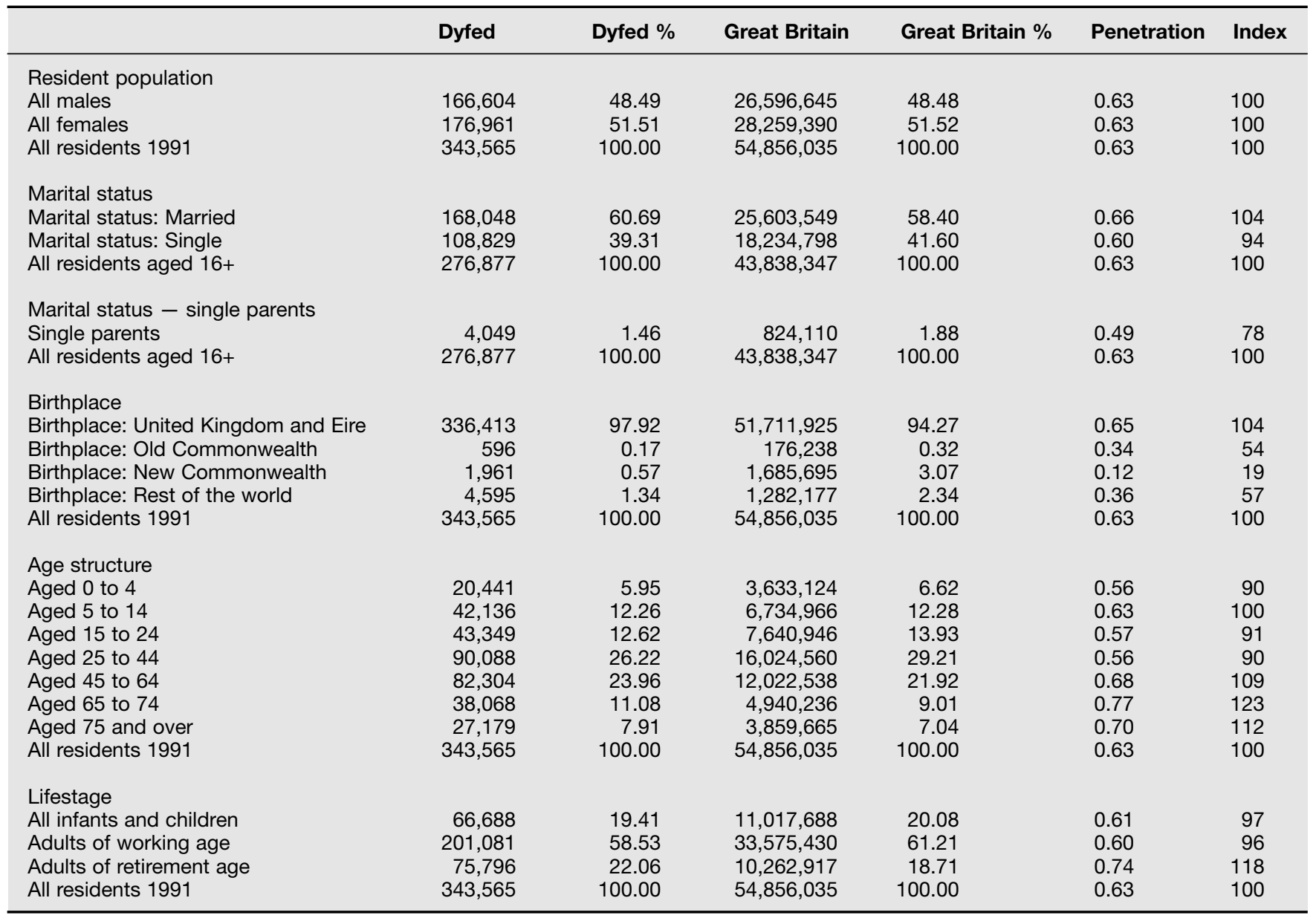

Source: Experian

\section{Use of geodemographic classifications}

In the past, users have tended to employ geodemographic classifications such as ACORN or MOSAIC for customer analysis, rather than 'raw' census variables. Now, with the commercial barriers against the census removed, users have a choice between the two sources. Some key benefits of each source are summarised in Table 2, from which it may be concluded that the census and geodemographic classifications are actually complimentary to one another, rather than competing with each other.

For 2001, the free access to census data should remove any cost barriers in profiling with raw variables, however, there will still be a place for 'off-the-shelf' geodemographic classifiers. A much larger number of these products can be expected to become available, given the free data, but this also opens up the possibility for users to build their own customised discriminators and information products.

\section{Customised discriminators}

The 2001 census represents an unprecedented opportunity for users to build their own customised 
Table 3: Example from customer profile report

\begin{tabular}{rlrrrrrr}
\hline & Ethnic types & $\begin{array}{l}\text { Profile } \\
\text { count }\end{array}$ & \multicolumn{1}{c}{$\begin{array}{l}\text { Base } \\
\text { population }\end{array}$} & \multicolumn{1}{c}{$\%$} & Z-Score & Index \\
\hline 1 & White & 35,143 & 94.7 & $51,873,794$ & 94.5 & 2 & 100 \\
2 & Black C'bean & 201 & 0.5 & 499,964 & 0.9 & -8 & 59 \\
3 & Black African & 141 & 0.4 & 212,362 & 0.4 & 0 & 98 \\
4 & Black Other & 81 & 0.2 & 178,401 & 0.3 & -4 & 67 \\
5 & Indian & 398 & 1.1 & 840,255 & 1.5 & -7 & 70 \\
6 & Pakistani & 464 & 1.3 & 476,555 & 0.9 & 8 & 144 \\
7 & Bangladeshi & 74 & 0.2 & 162,835 & 0.3 & -3 & 67 \\
8 & Chinese & 234 & 0.6 & 156,938 & 0.3 & 12 & 221 \\
9 & Asian & 146 & 0.4 & 197,534 & 0.4 & 1 & 109 \\
10 & Other & 210 & 0.6 & 290,206 & 0.5 & 1 & 107 \\
& & & & $54,888,844$ & 100.0 & & \\
\hline
\end{tabular}

Profile: Sample customers

Base: GB 1991 census population

Source: $\mathrm{CACl}$

discriminators and information products, for two main reasons. First, as noted above, the new commercial terms for census access mean that the data are available effectively free of charge: in the past, the charges for bulk use of the small area statistics database were prohibitive. Secondly, the continuous increase in desktop processing power and decrease in computer costs, that has been witnessed since the 1990s means that multivariate analysis for geodemographic development can easily be undertaken on a powerful and inexpensive PC.

Heavy users of geodemographics will probably benefit from building their own information products based upon the 2001 census data. Comparative studies have shown that the standard 'off-the-shelf products built from similar sources tend to show broadly similar levels of performance. To obtain improvements one must include more discriminatory variables and/or shift from area level to individual level classifications.

Customised discriminators will take many forms and will integrate a number of data sources: census, customer data and market research are just the starting point. Three such approaches follow and they are discussed in turn below.

- area classifications built using a combination of customer and census data;

- census-based targeting models to predict various outcomes, such as response to a recruitment campaign or future customer value;

- estimates of consumer demand based upon demographic modelling using market research data.

\section{Customised area classifications}

By extracting customer data without sampling and summarising at an appropriate level of geography, a new set of variables can be constructed which describes customer behaviour across each area. These variables may then be analysed jointly with census variables for the same areas in order to build area classifications. Examples of such customer variables might be:

- for a bank: average debit turnover per area (indicating earned income level), transaction rates, product holdings;

- for a retailer: average expenditure per customer on each product category;

- for a telephone company: average revenues and calls per customer. 
Table 4: Key benefits of census variables and geodemographics

Census variables
Describe people and households residing in areas
Same questions can be included in customer surveys
Raw ingredients for bespoke information product developments

Geodemographic classifications

Describe areas according to profiles of their residents

Intensive development and interpretation goes into each development

Can provide greater insight into populations living in each type of area

Three options exist for the use of customer and census variables at this stage.

Option 1: Use customer variables to select discriminatory census variables, build classification from those census variables.

Option 2: Build the classification using a combination of the most discriminatory customer and census variables.

Option 3: Build the classification using customer variables only, interpret area types using census variables.

Each option has its merits - in a given situation, the 'right' choice will depend upon business objectives and 'what works best'. Option 1 is probably the 'traditional' approach and so is known to 'work' fairly well. Option 2 includes customer variables that ought to improve performance, and so might give the most powerful end result. Option 3, which is more of an innovation, has the advantage that the classification may be regularly updated using the latest customer data and so will not deteriorate in quality over time. (As the census currently operates on a ten-year cycle, the data may become inaccurate over time, especially in areas of rapid change.)

Of course, having assembled the appropriate data set of areas, their census data and customer variables, each option may be tested with relative ease in order to assess the value of the classification.

\section{Census-based targeting models}

Census data may be included in targeting models alongside customer variables, however, actual customer behaviour and demographics tend to be stronger predictors than area-based data. Therefore, in most cases, the census variables end up being dropped out of the model.

Census variables, however, can help to model the value of each OA in terms of potential for customer recruitment and future value.

Provided that the outcome to be predicted is linked to certain demographic characteristics, a model using raw census variables is likely to outperform a standard geodemographic classification. When evaluating the custom-built model, it is still helpful to use a geodemographic classifier as a benchmark of performance, in order to decide whether there is sufficient gain to justify the bespoke approach.

\section{Consumer demand estimates}

Market research surveys take over from the census when it comes to measuring demand or consumption for various products. Research data are costly to collect, however, and therefore most surveys are operated on a sample basis the main exception obviously being the census. So while market research data are sampled too 'thinly' to provide direct estimates for every census $\mathrm{OA}$ if the data 


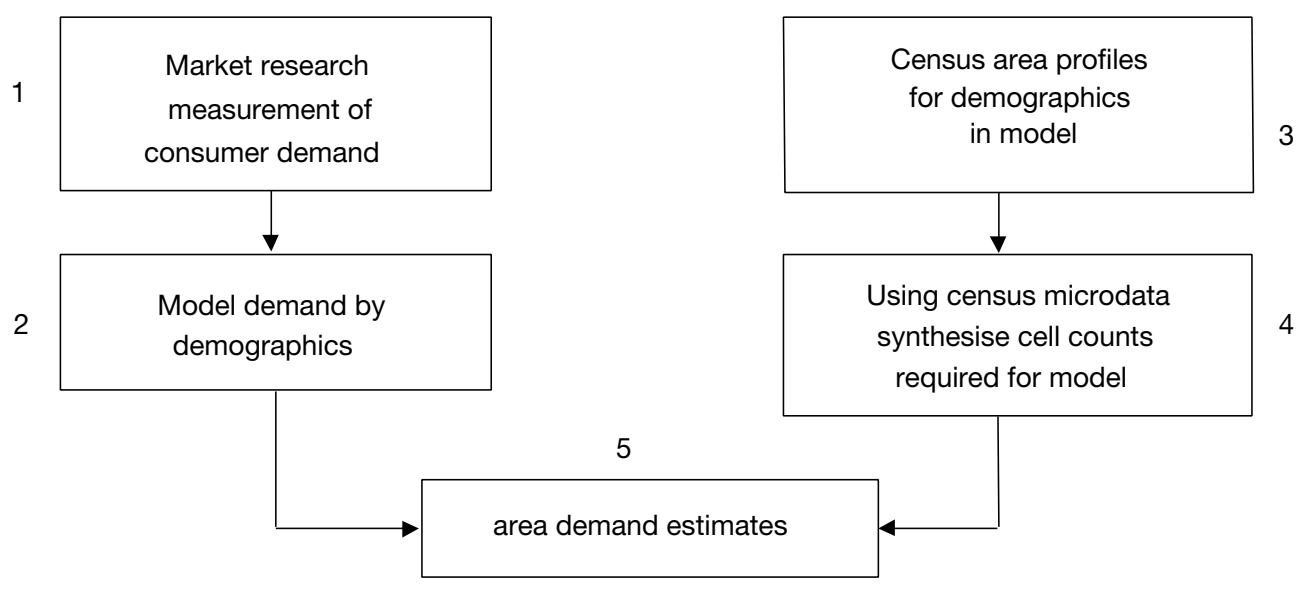

Figure 1 Generating small area estimates of consumer demand

can be modelled using common demographics available in both sources, then the models can be applied to give estimates for all OAs. ${ }^{7}$

This approach, illustrated in Figure 1, was applied several years ago to generate small area market size estimates for a retailer at the level of the 1991 census enumeration districts. The project entailed a large number of stages, however each could be tested before moving onto the next. And as with the other customised developments that have been discussed, the results should be evaluated against the standard geodemographic approach for estimating area potential.

Another census output, known as census microdata, was particularly useful in this project and has applications more widely for customer analysis. Census microdata essentially consists of individual level data sets for households and persons sampled from the census output database (samples of anonymised records). ${ }^{8}$ These data allow relationships to be analysed between any of the variables captured in the census; in this case enabling population counts to be estimated for the demographic cells required by the demand models.

\section{CONCLUSIONS}

The outputs from the 2001 census have been designed to be more robust and more actionable at a small area level. Given the removal of data charges, users will be able to apply the census as never before, for demographic and locational analysis.

With the free data and powerful computing resources, users may integrate the census with their own customer databases to gain business advantage from building customised analytics and information products.

\section{References}

1 Dugmore, K. and Moy, C. (eds) (2003) '2001 Census: A tool for gaining business advantage' (working title) in preparation, The Stationery Office, London.

2 Leventhal, B. (2003) 'Developments in outputs from the 2001 Census', International Journal of Market Research, Vol. 45, Quarter 1, pp. 3-19.

3 MRS (2001) 'Geodemographics Knowledge Base', www.geodemographics.org.uk

4 ONS (2001) '2001 Census Home Page', www.statistics.gov.uk/census2001

5 Martin, D. (2002) 'Geography for the 2001 Census in England and Wales', Population Trends No. 108, Office for National Statistics.

6 Meier, E. and Moy, C. (2003) 'Social grading and the census' (in preparation), International Journal of Market Research.

7 Rao, J. N. K. (2003) 'Small area estimation', Wiley, Chichester.

8 For more information on census microdata see www.ccsr.ac.uk/sars 